\title{
The vagaries of paraphrase: a reply to Holton on the counting problem
}

\section{IAN RUMFITT}

According to the paratactic theory of indirect discourse, a report in the form ' $A$ said that $p$ ' is best regarded as an utterance of two type sentences, ' $A$ said that' and ' $p$ ', in which the word 'that' is a demonstrative pronoun somehow relating to the subsequent (non-assertive) utterance of ' $p$ '. Different versions of the theory, however, differ markedly over the nature of this relation, and over the character of the item which the putative demonstrative designates. In the paper which brought the theory to widespread attention, Davidson (1969) construed the demonstrative as denoting the speech event which is the subsequent utterance of ' $p$ '. Accordingly, he construed the initial claim ' $A$ said that' as expressing a relationship between a person $A$ and an event $u$-a relation that obtains iff $u$ and some utterance of $A$ 's 'make samesayers' of the reporter and $A$. Against this, Ian McFetridge (1976) raised what has come to be called the 'counting problem'. Our actual practice of making indirect reports, he claimed, is littered with examples which show that the designata of the grammatical objects of the verb 'to say' (the things said, as we might call them) cannot be particular utterances. And he went on to develop a variant paratactic theory in which the demonstrative is taken to be a device of 'deferred ostension' - denoting, not the ensuing utterance itself, but the proposition which that utterance expresses, or binds. ${ }^{1}$ On this view, 'to say' expresses a relation between speakers and the things expressed by utterances, and not between speakers and utterances themselves. The most recent contribution to this intrafamilial wrangle has come in these pages from Richard Holton (1996), who disputes the whole cogency of McFetridge's attack on Davidson. This note is devoted to explaining why his counter is unconvincing.

McFetridge undertook to produce cases in which the designata of the demonstrative (the things said) cannot be taken to be speech events; and in so doing, he concentrated upon examples in which there is an explicit claim to the effect that the thing said on one occasion of utterance (the proposition thereby expressed) is (or is not) identical with the thing said on another. As Holton rightly observes, such examples do not tax Davidson's strategy of reconstruing predicates - a strategy already visible in his

${ }^{1}$ For the difference, see McFetridge 1976 and my 1993. The latter article proposes a new strain of McFetridge's variant theory, as does Wiggins 1992. 
account of 'to say'. For even if we accept that it makes sense to say (for example) 'The proposition that Quine is older than Davidson is the very same thing as the proposition that Davidson is younger than Quine', and subject this claim to a paratactic treatment, it is apparently open to Davidson to understand the term 'proposition' as a count noun applying to a certain kind of utterance, and to construe the entire claim as true iff the reporter's utterances of 'Quine is older than Davidson' and 'Davidson is younger than Quine' make him a samesayer with himself. However, as Holton recognizes, explicit identity statements of this form are not the only cases which may reflect identity or diversity as between things said:

[There] do seem to be other times when the explicit quantifiers of English do not range over utterances, but over whatever it is that the utterances are utterances of:

(12) Galileo said only one thing that night, but he said it over and over again.

Obviously, we can't understand the quantifier 'only one thing' as ranging over utterances, since if (12) is true Galileo made many utterances. So in what sense is it true that he said only one thing?...A natural way of construing (12) is to think of the quantifier as ranging over propositions (1996: 48).

But, Holton argues, Davidson should remain unperturbed by such cases. It is no surprise, he says,

that Davidson will not be able to take sentences like (12) at face value. Any theorist of ordinary language who eschews propositions will be in the same position .... The interest ... lies in determining whether he has the resources to give convincing paraphrases.

Here Davidson is not badly placed. Given his analysis of speech ascriptions, he already has the samesayer relation. The obvious move is to paraphrase apparent quantification over propositions in terms of this relation. Admittedly, this will require straying some way from the surface syntax, but Davidson is already committed to that. Thus (12) can be represented as

(13) Galileo made many utterances that night, and $(\forall x)(\forall y)$ (if $x$ is amongst those utterances, and $y$ is amongst those utterances, then $x$ and $y$ made Galileo a samesayer with himself) (op. cit., 49).

But, as I shall argue, serious problems lie concealed within the phrase 'has the resources to give convincing paraphrases'.

In order to see what these might be, it helps to step back for a moment and consider the aims of the enterprise to which the paratactic theory is 
supposed to contribute. That enterprise is, of course, the construction of an adequate semantical theory for English, where such a theory will be adequate if it 'explicitly states something knowledge of which would suffice for interpreting [i.e. assigning the right truth conditions to, English] utterances' (Davidson 1976: 171). As Davidson remarks in another place, the construction of such a theory for a natural language will 'almost certainly divide into two stages. In the first stage, truth will be characterized, not for the whole language, but for a carefully gerrymandered part of the language. This part, though no doubt clumsy grammatically, will contain an infinity of sentences which exhaust the expressive power of the whole language. The second part [= stage?] will match each of the remaining sentences to one or (in the case of ambiguity) more than one of the sentences for which truth has been characterized' (1973: 133).

To which of these parts do Holton's sentences belong? It is fairly clear that (12) cannot belong to the first part. Davidson's truth theories are not only homophonic, but also generate proofs of T-theorems that reflect the structure of the quoted sentences. Accordingly, a theory of this kind which applied to sentences like (12) would involve the theorist in quantifying over the things said on occasions of utterances, as well as the utterances themselves; such quantification would not be confined to the speakers the theorist was trying to interpret. Since Davidson aspires to avoid quantification of this kind, sentences like (12) must belong to the second part of English, and as such they must derive their truth conditions from some anchor sentence in the first part. This anchor cannot be exactly (13), for (13) is not a sentence of English. I shall, however, suppose that Holton would be prepared to advance as such an anchor an English rendering of (13) - as it might be (13'), 'Galileo made many utterances that night, and any two among them make him a samesayer with himself'. For only in this way will his remark about paraphrases constitute a defence of Davidson's position. It should be noted, however, that this gives to the notion of samesaying a greater role in the elaboration of the paratactic theory than Davidson himself accords to it. In his book, it appears only in an informal gloss on the notion of saying (see 1969: 104, n.14). In Holton's, it figures in the fragment of English to which the truth theory directly applies.

If, though, the total theory is to state something sufficient for interpreting the utterances that English speakers actually produce, it will have to state something sufficient for effecting the right match between sentences in the two parts. ${ }^{2}$ That is to say, it will have to include rules of paraphrase which pair sentences outside the semantical kernel with those the semantics is capable of treating 'at face value', i.e. those to which the truth theory applies. In the present case, then, we shall need rules for matching English sentences which involve apparent quantification over propositions with 
others that do not. What is more, if they are to be of any interest to Davidson, these rules must be of a particular kind. A completed semantical theory is supposed to 'demonstrate in a persuasive way that the language, though it consists in an indefinitely large number of sentences, can be comprehended by a creature with finite powers' (1969: 94), an explanatory onus from which Davidson derives a requirement of finite axiomatizability on the truth theory which applies to the gerrymandered core. But if it is reasonable to impose such a requirement on the core, it must also be reasonable to impose a similar constraint on the rules of paraphrase; otherwise we should be left without a 'persuasive' demonstration of how a finite training could have enabled us to know which sentence(s) in the core give the truth conditions of those that we actually use. In any event, the general point will be clear. Holton does not provide any rules of paraphrase and, for so long as they remain absent, the intuitive acceptability of (13) or (13') as a paraphrase of (12) - the fact that it is 'convincing' - should not blind us to the fact that (12) remains outside the pale of sentences for which the eschewer of propositions is capable of providing a proper semantics. No such objection, however, besets the defender of the variant paratactic theory. Called upon to answer the question "What is the word 'it" doing in sentence (12)?', he can reply that it is playing its familiar role of variable (in this case, one bound by the numerical quantifier 'only one') - just as the pronoun 'him' does in 'Galileo insulted only one cardinal that night, but he insulted him over and over again'. (For the 'What is this word doing here?' question, see Davidson 1969: 94.)

Is there any prospect of finding such rules as Holton's account requires? The task is, of course, one for him, but it does seem utterly daunting. It is hard enough to articulate general rules that subsume the paraphrases in Holton's own short paper, let alone construct an effective method for paraphrasing every English sentence involving apparent quantification over things said. Moreover, the fact that we know that $(13)$ and $\left(13^{\prime}\right)$ are paraphrases of (12) is no argument for supposing that there must be rules of the appropriate kind. For the explanation might be that we first apply to (12) the knowledge made explicit by a variant, McFetridgean paratactic theory, and then deduce that utterances of $(12)$ and $\left(13^{\prime}\right)$ are true in precisely the same circumstances via the general principle that a single proposition will be repeatedly uttered precisely on occasions in which there are many utterances

2 See Davidson 1967: 123: "The ideal implicit in the paper [= "The logical form of action sentences"] is a theory that spells out every element of logical form in every English sentence about actions. I dream of a theory that makes the transition from the ordinary idiom to canonical notation purely mechanical, and a canonical notation rich enough to capture, in its dull and explicit way, every difference and connection considered the business of the theory of meaning' (emphasis added). 
which render their utterers samesayers. A congruence of truth conditions, provable on the basis of semantic principles, is certainly an exigent condition for paraphrase; but the suggested explanation of how we come to know that $\left(13^{\prime}\right)$ paraphrases (12) is evidently unavailable to a theorist who refuses to quantify over propositions in formulating his truth theory.

To be sure, a proponent of the variant paratactic theory incurs obligations that Davidson himself avoids. In particular, he must explain what it is for two utterances to express the same proposition, and how it is that the putatively demonstrative 'that' secures reference to one such. I have tried to show how Davidson's own notion of an interpretative truth theory helps us to discharge these obligations (1993). While that explanation could doubtless be improved, its prospects - and the prospects for a completed paratactic semantics along 'variant' lines - are surely better than those of its nominalistic rival, which must live in hope of a supplementation of which we have, as yet, not the slightest inkling.

$$
\begin{array}{r}
\text { The University of Michigan } \\
\text { Ann Arbor, MI, 48109-1003, USA } \\
\text { rumfitt@umich.edu }
\end{array}
$$

\section{References}

Davidson, D. 1967. Reply to Lemmon on tenses. In his Essays on Actions and Events, 123-24. Oxford: Clarendon Press, 1980.

Davidson, D. 1969. On saying that. In his 1984, 93-108.

Davidson, D. 1973. Radical interpretation. In his 1984, 125-39.

Davidson, D. 1976. Reply to Foster. In his 1984, 171-79.

Davidson, D. 1984. Inquiries into Truth and Interpretation. Oxford: Clarendon Press. Holton, R.J. 1996. Davidson, McFetridge, and the counting problem. Analysis 56: 4650 .

McFetridge, I.G. 1976. Propositions and Davidson's account of indirect discourse. Proceedings of the Aristotelian Society 76: 131-45.

Rumfitt, I. 1993. Content and context: the paratactic theory revisited and revised. Mind 102: 429-54.

Wiggins, D. 1992. Meaning, truth-conditions, proposition: Frege's doctrine of sense retrieved, resumed and redeployed in the light of certain recent criticisms. Dialectica 46: 61-90. 